\title{
Hotel Spa Internasional Di Bali Dengan Pendekatan Arsitektur Regionalisme
}

\author{
Shabrina Adani, Widi Suroto, Ofita Purwani \\ Program Studi Arsitektur \\ Universitas Sebelas Maret Surakarta \\ Email: shabrinaadani92@gmail.com
}

\begin{abstract}
Designing International Hotel \& Spa in Bali is motivated by the growing number of domestic and foreign tourists visit in the field of tourism and business, the increasing number of distribution of tourist attraction in Bali, and the efforts to preserve Balinese spa as the cultural activity. There are modern and traditional elements of human needs at the background, so the purpose of this scheme is to offer traditional spa function on an international standard hotel in order to support tourism in Bali with a building design that shows smelting architecture of the present and the past through regionalism architecture. The issue is: how to design a commercial building that is multifunctional hotel and spa in Bali that have international standards using the approach of regionalism architecture as a design methodology. The result is the application of architectural regionalism Bali concretely in the form of buildings, building appearance and layout of the hotel building and spa.
\end{abstract}

Keywords: Hotel, Regionalism Architecture of Bali, Spa

\section{PENDAHULUAN}

Bali merupakan sebuah pulau kesatuan wilayah dari Pemerintah Provinsi yang ada di Indonesia. Bali dikenal sebagai tujuan liburan bagi wisatawan Nusantara dan mancanegara karena Bali memiliki obyek wisata yang sangat beragam, baik wisata alam, wisata budaya, dan wisata bahari yang tersebar di tiap daerah kabupaten.

Berdasarkan data Badan Pusat Statistik (BPS) Provinsi Bali ${ }^{1}$, jumlah wisatawan mancanegara yang datang melalui Bandara Ngurah Rai mengalami kenaikan sebesar 16,09 persen pada bulan April tahun 2014 bila dibandingkan dengan bulan yang sama di tahun sebelumnya. Tercatat jumlah kunjungan wisatawan pada tahun 2009 - 2013 terus meningkat berdasarkan 10 besar kunjungan obyek wisata yang paling terkenal di Bali di setiap tahunnya (Gambar 1). Dinas Pariwisata Bali pun mencatat jumlah kunjungan wisatawan nusantara dan mancanegara dari potensi obyek wisata yang dimiliki di setiap kabupaten/ kotamadya mencapai 10.332 .670 juta orang di tahun 2013. Hal ini karena Bali

\footnotetext{
1 "Berita Resmi Statistik Provinsi Bali No. 35/06/51/6 Th. VIII."

${ }^{2}$ Gubernur Bali, "PERATURAN DAERAH PROVINSI BALI NOMOR 16 TAHUN 2009
}

memiliki sebaran daya tarik wisata di luar kawasan pariwisata dan Kawasan Daya Tarik Wisata Khusus (KDTWK) tiap kabupaten/kota. Tercatat terdapat 159 lokasi wisata yang sedang berkembang dari tahun 2009 hingga 2029. ${ }^{2}$ Selain itu, masyarakat Bali masih sangat menjaga tradisi leluhur seperti menjadikan spa membudaya hingga saat ini dan salah satu penyokong sektor pariwisata pula. Prestasi yang membanggakan diraih oleh Bali dalam bidang spa ialah "The Best Destination Spa in The World" ${ }^{3}$ yang didapatkan ketika Bali sebagai tuan rumah Global Spa Summit 2011. Sehubungan dengan kegiatan tersebut, Hotel Spa merupakan wadah yang dapat menunjang kegiatan kepariwisataan dan bisnis di Bali.

Peleburan fungsi yang berlatar belakang kebutuhan manusia secara modern dan tradisional ini menjadi pertimbangan bentuk fisik Hotel Spa yang akan dibangun. Arsitektur masa kini didominasi oleh teknologi, sedangkan budaya tradisional Bali

Tentang Rencana Tata Ruang Wilayah Provinsi Bali 2009-2029."

3 "Artikel Berita Dari Website Martha Tilaar Salon Day Spa." 
ditentukan terutama oleh seni dan agama. ${ }^{4} \mathrm{Di}$ lain sisi, Bali banyak dikunjungi oleh wisatawan baik dari luar dan dalam negeri yang mengharapkan nuansa yang berbeda dari tempat asal mereka, ${ }^{5}$ untuk itu dibutuhkan rancang bangun yang mampu merepresentasikan kelokalan daerah Bali.

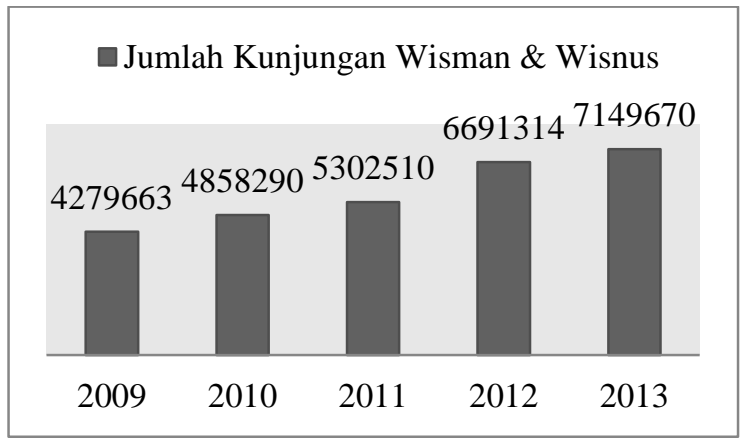

Gambar 1. Jumlah Kunjungan Wisatawan Berdasarkan 10 Obyek Wisata di Bali

(Sumber: Dinas Pariwisata Kabupaten/Kota Se Bali, 2013)

Penulis memutuskan menggunakan Arsitektur Regionalisme sebagai metode dalam pendekatan obyek rancang bangun karena mampu menghadirkan nuansa tradisi Bali dengan gaya masa kini. Arsitektur Regionalisme merupakan gerakan dalam perancangan yang lebih ingin menampilkan identitas daerah dan universal yang mampu melebur dalam satu bangunan. ${ }^{6}$ Maka dari itu, perencanaan Hotel Spa diharapkan menghasilkan bangunan yang menggabungkan masa lalu dan masa kini, regional dan universal serta dapat mengakar dalam pada tradisi daerah Bali. ${ }^{7}$

\section{METODE}

Metode yang digunakan pada perancangan Hotel Spa di Bali terbagi

\footnotetext{
${ }^{4}$ Budihardjo, Architectural Conservation in Bali, 94.

${ }^{5}$ Urry, The Tourist Gaze, 3.

${ }^{6}$ Jencks, The Language of Post-Modern

Architecture; Canizaro, Architectural

Regionalism, 103 Pendapat Suha Ozkan dalam

Regionalism within Modernism.

${ }^{7}$ Canizaro, Architectural Regionalism, 57

Pernyataan Harwell Hamilton Harris pada buku

Regionalism and Nationalism in Architecture

(1958). ibid., 67 Materi diambil dari jurnal organisasi, North Carolina Architect, oleh Harwell H. H, isu spesial tentang Regionalism
}

menjadi pencarian data, analisis data, dan hasil analisis data.

Pencarian data dibedakan menjadi dua bagian yaitu data primer meliputi survey lapangan dan wawancara dari sumber-sumber yang diperlukan untuk mendapatkan masukan; data sekunder meliputi data dari instansi terkait dan buku-buku literatur. Literatur yang digunakan antara lain membahas tentang:

a. Pengertian, fungsi, jenis, dan fasilitas Hotel Spa ${ }^{8}$.

b. Peruangan hotel yang sesuai standar internasional ${ }^{9}$ yang dipertemukan dengan spa tradisional $\mathrm{Bali}^{10}$.

c. Arsitektur Regionalisme ${ }^{11}$ dan bangunan yang berkembang di Bali ${ }^{12}$.

Analisis data dalam perencanaan dan perancangan Hotel Spa di Bali digunakan untuk memecahkan masalah melalui pendekatan Arsitektur Regionalisme terhadap permasalahan dan persoalan perencanaan Hotel Spa di Bali. Terdapat 3 permasalahan pokok di perencanaan dan perancangan ini ialah tapak, ruang, dan bentuk. Hasil analisis digunakan untuk menentukan konsep perencanaan dan perencanaan sebagai dasar untuk menuju tahap desain fisik.

\section{ANALISIS}

\subsection{Analisis Peruangan dan Luasan Ruang}

Analisis peruangan adalah sebagai faktor penting dalam menentukan luasan ruang yang direncanakan. Luasan ruang dianalisis melalui kelompok kegiatan, di mana pelaku dikelompokan sesuai kegiatan yang dilakukan di Hotel Spa.

1. Tujuan: memperoleh jenis kebutuhan ruang.

2. Dasar pertimbangan: pengelompokan kegiatan dan pelaku kegiatan

(1978). Curtis, Regionalism in Architecture, 7374; Widyarta, Mencari arsitektur sebuah bangsa, 47.

${ }^{8}$ Marlina, Panduan Perancangan Bangunan

Komersial.

${ }^{9}$ Neufert, Data Arsitek; De Chiara and Callender, Time Saver Standards for Building Types 2nd Edition.

${ }^{10}$ Jumarani, The essence of Indonesian spa.

${ }^{11}$ Canizaro, Architectural Regionalism.

${ }^{12}$ Gelebet and Puja, Arsitektur Tradisional

Daerah Bali; Budihardjo, Architectural

Conservation in Bali. 
3. Analisis:

Konsep analisis pengguna di Hotel Spa adalah:
a. Tamu Hotel Spa
b. Pengunjung Hotel Spa
c. Pengelola Hotel Spa
d. Pegawai Hotel Spa

Berikut total luasan ruang yang dibutuhkan berdasarkan kelompok kegiatan:
a. Area penerimaan: $3520,1 \mathrm{~m}^{2}$
b. Area lobi: $431,22 \mathrm{~m}^{2}$
c. Fasilitas khusus: $2294,63 \mathrm{~m}^{2}$
d. Fasilitas hunian: $7099,76 \mathrm{~m}^{2}$
e. Area pengelola: $463,88 \mathrm{~m}^{2}$
f. Fasiltas spa: $467,66 \mathrm{~m}^{2}$
g. Fasilitas olahraga: $815,62 \mathrm{~m}^{2}$
h. Area food \& beverages: $1818,48 \mathrm{~m}^{2}$
i. Area tata graha: $437,64 \mathrm{~m}^{2}$
j. Area servis: $531,7 \mathrm{~m}^{2}$

\subsection{Analisis Pengolahan Tapak}

1.Tujuan: menentukan pencapaian, entrance, orientasi, view, penyikapan terhadap klimatologis, dan zoning.

2.Dasar pertimbangan: eksiting dan kondisi klimatologis tapak.

3. Analisis:

a.Pencapaian dan entrance (Gambar 2)

Dasar pertimbangan pencapaian :

1) Kondisi dan potensi jalan di sekitar tapak.

2) Arus lalu-lintas jalan.

3) Kemudahan akses baik menggunakan kendaraan pribadi maupun transportasi umum.

4) Kemanan dan kenyamanan bagi penggunan jalan maupun pengunjung bangunan.

5) Analisis pencapaian digunakan untuk menentukan main entrance dan side entrance.

Dasar pertimbangan entrance :

1) Berhubungan langsung dengan jalan besar (jalan utama) sehingga mudah dikenali.

2) Kemudahan akses bagi kendaraan, maupun pejalan kaki.

3) Mengarahkan pengunjung menuju bangunan.

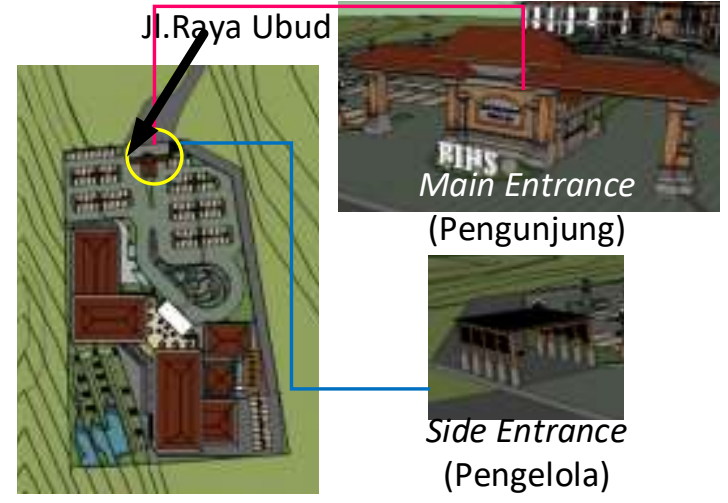

Gambar 2. Pencapaian dan Entrance

b. Orientasi dan view (Gambar 3, 4) Dasar pertimbangan orientasi dan view:

1) Kondisi dan arus kendaraan di jalan sekitar tapak.

2) Arah datang pengunjung terbanyak.

3) Potensi lingkungan sekitar.

4) Arah pandang dari lingkungan sekitar untuk menentukan nilai ekspos tertinggi.

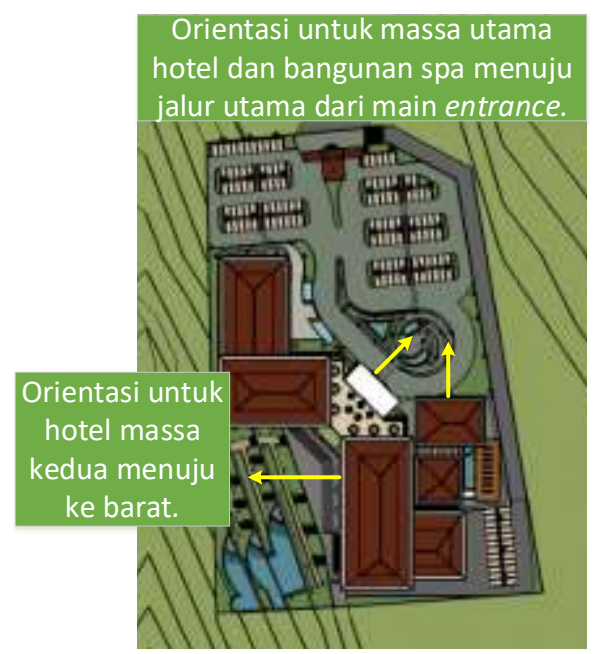

Gambar 3. Orientasi Bangunan 


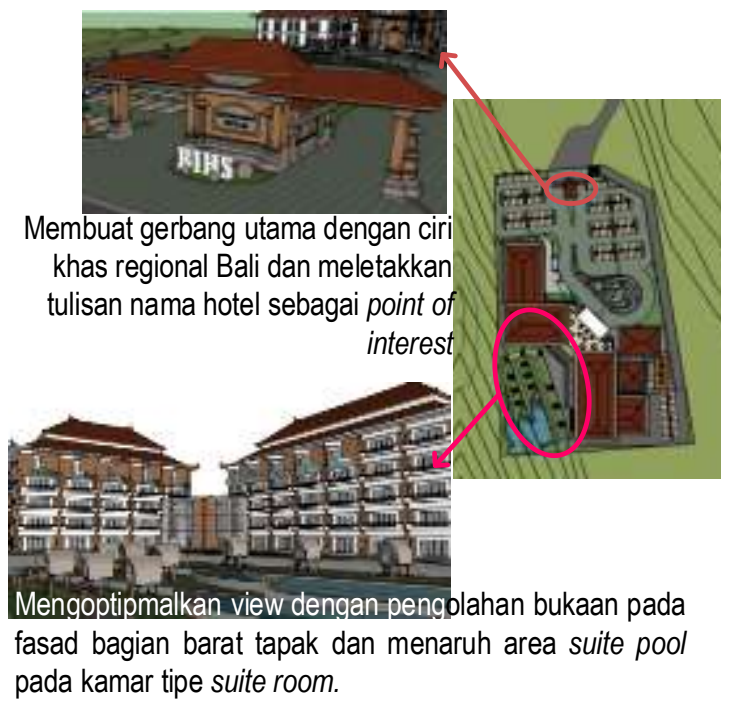

Gambar 4. Konsep Tampilan terhadap View

c. Penyikapan terhadap klimatologis

Di Bali, wisatawan memiliki kecenderungan tidak peduli dengan teriknya matahari karena euforia liburan yang lebih penting untuk dipenuhi kebutuhannya. Momen matahari terbit dan matahari terbenam menjadi sangat wajib untuk dinikmati oleh wisatawan. Berikut penyikapan desain terhadap klimatologis:

1) Fasad bangunan untuk Hotel dan Spa sisi timur diberikan bukaan yang maksimal dan diberikan sky garden agar pengguna bisa mendapatkan kehangatan matahari pagi dan momen matahari terbit.

2) Pemberian barrier untuk pemecah angin dan penyaring debu. Serta menambahkan elemen air seperti kolam untuk penyejuk panasnya terik matahari siang.

3) Peletakkan ruang publik seperti kolam renang dan restoran yang menghadap ke arah barat sehingga wisatawan dapat menikmati matahari tenggelam dengan berbagai macam kegiatan.

\footnotetext{
${ }^{13}$ Canizaro, Architectural Regionalism, 103

Pendapat Suha Ozkan dalam Regionalism within Modernism.

${ }^{14}$ Budihardjo, Architectural Conservation in Bali, 39 istilah untuk urutan hirarki pada tri angga dari yang paling rendah ke yang paling tinggi.
}

Selain itu bagian hotel yang menghadap barat juga diberikan balkon. Pengaplikasian sun shading pada bangunan untuk menghindari silaunya matahari.

\subsection{Analisis Bentuk dan Tatanan Massa}

Pembahasan mengenai bentuk di dalam konsep ini berupa pendekatan Arsitektur Regionalisme Bali pada Hotel Spa. Kuatnya nilai arsitektur berdasar-kan filosofi-filosofi dari kepercayaan masyarakat Bali dan ditunjang oleh ragam hias khas Bali dan material ekspos, menjadi salah satu ciri dari jenis regionalisme yaitu "concrete regionalism" ${ }^{13}$. Konsep bentuk pada Hotel Spa yang akan dibahas berikut adalah bentuk massa, tampilan massa, pola tata massa, dan tata lansekap:

\section{Bentuk massa}

Penggunaan filosofi tri angga (Gambar 5), seperti konsep anatomi manusia yang terdiri dari kaki, badan, dan kepala (nista - madyautama ${ }^{14}$ ), pada rumah Bali sudah menjadi ciri khas bentuk bangunan regional Bali.

\section{Tampilan massa}

Masyarakat Bali rata-rata merupakan seniman sehingga ornamen/ragam hias pada bangunan menjadi salah satu komponen penting. ${ }^{15}$ Selain itu, tampilan pada bangunan rumah dan gerbang di Bali juga banyak menampilkan "material ekspos" 16 yang juga menjadi ciri khas bangunan.

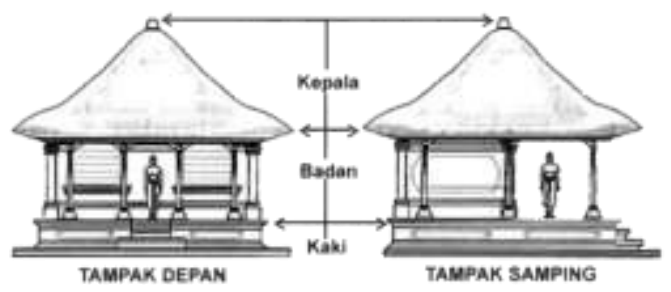

Gambar 5. Filosofi Tri angga

(Sumber: ma3dhy.blogspot.com)

\section{Pola tata massa}

Selaras dengan konsep bentuk massa bangunan, konsep tri angga dalam analisis secara horizontal disebut tri mandala. ${ }^{17} \mathrm{Tri}$ mandala sangat berkaitan dengan pola tata

\footnotetext{
${ }^{15}$ Ibid., 88.

${ }^{16}$ Ibid., 50.

${ }^{17}$ Ibid., 41.
} 
massa (Gambar 6). Dari dalam tapak, peletakan massa ini akan menjadi sebuah pengarah untuk menunjukkan karakter budaya Bali.

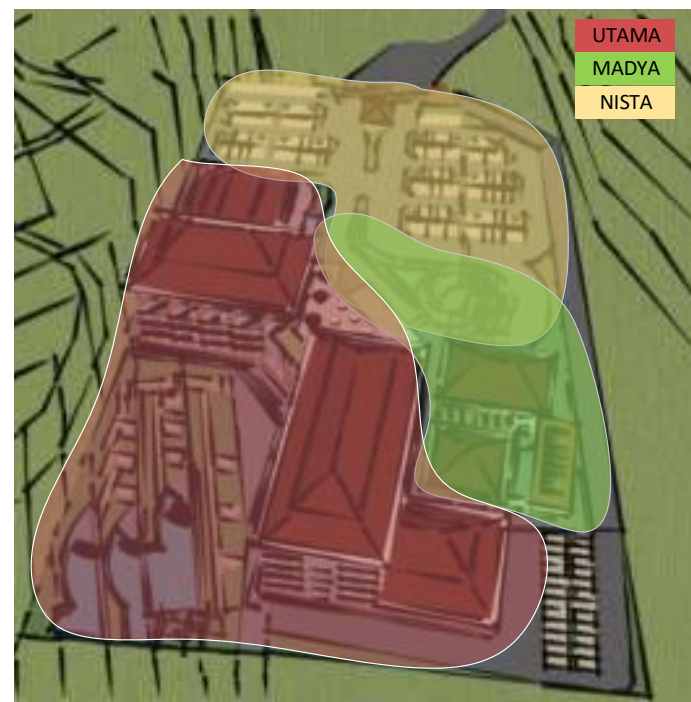

Gambar 6. Pembagian Zona pada Hotel Spa Berdasarkan Tri Mandala

\section{Tata lansekap}

Konsep natah (pelataran dalam) pada rumah Bali diaplikasikan ke dalam lansekap Hotel Spa. Natah di Bali memiliki konsep open space berupa taman. (Gambar 7)
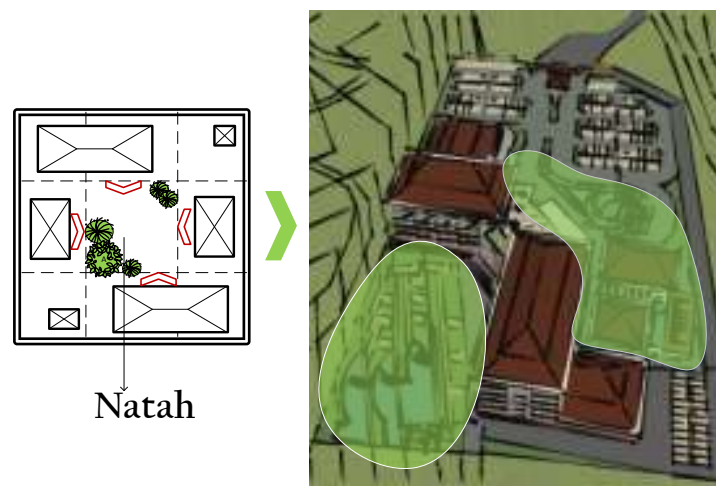

Gambar 7. Peletakan Natah (Taman) di antara Massa Satu dengan Lainnya

\section{KESIMPULAN (KONSEP DESAIN)}

Berdasarkan hasil analisis perencanaan dan perancangan yang dilakukan, maka diperoleh konsep desain Hotel Spa Internasional di Bali dengan Pendekatan Arsitektur Regionalisme sebagai berikut:

Lokasi : Jalan Raya Ubud, Ubud, Kabupaten Gianyar, Bali.

Luas Lahan $\quad: \pm 21592 \mathrm{~m}^{2}$

Luas Bangunan : $\pm 17880,684 \mathrm{~m}^{2}$
Jumlah Lantai : 1-5 Lantai

Penerapan Arsitektur Regionalisme pada bangunan Hotel Spa di Bali dikhususkan kepada unsur-unsur fisik bangunan dengan mengguna-kan pendekatan regionalisme secara konkrit. Permasalahan arsitektural yang diselesaikan oleh regionalisme adalah peruangan, tapak, dan bentuk. Desain bangunan Hotel Spa yang memiliki unsur filosofi tri angga pada bentuk massa (Gambar 8), pengaplikasian ragam hias Bali pada interior (Gambar 9), penggunaan material ekspos (Gambar 10) dan pengolahan lansekap menggunakan filosofi tri mandala (Gambar 11) dan natah (Gambar 12).

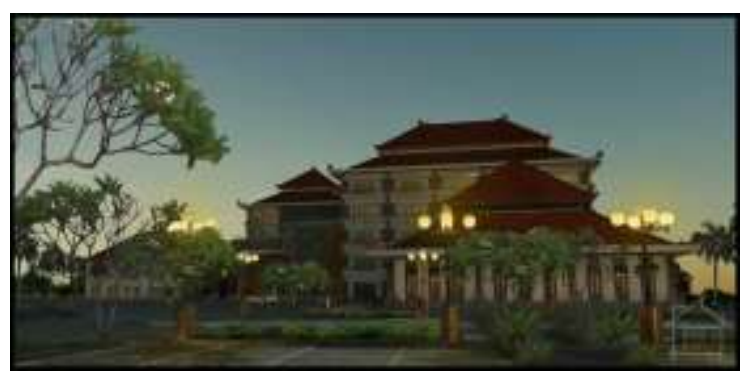

Gambar 8. Eksterior Hotel Spa

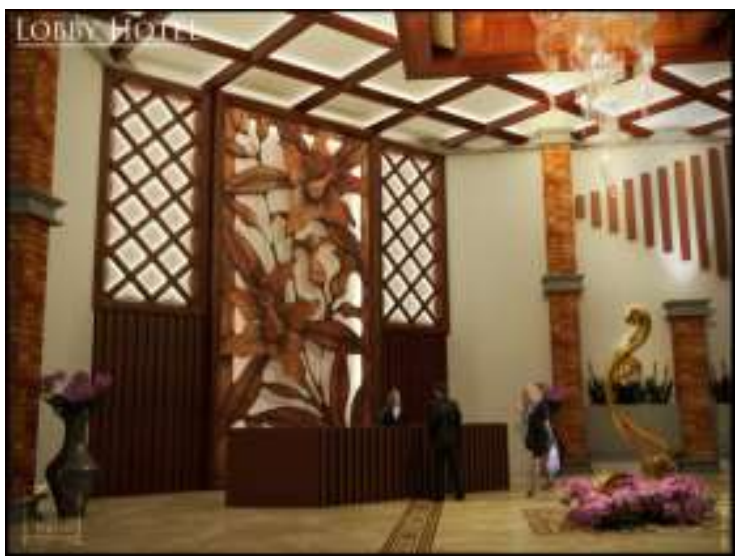

Gambar 9. Interior Lobi Hotel

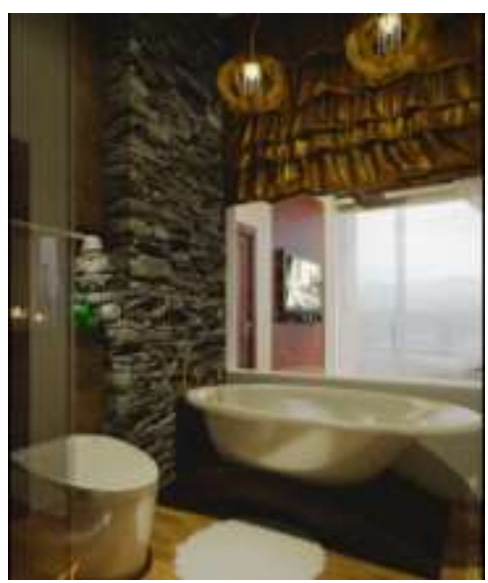

Gambar 10. Interior Kamar Mandi Suite Room 


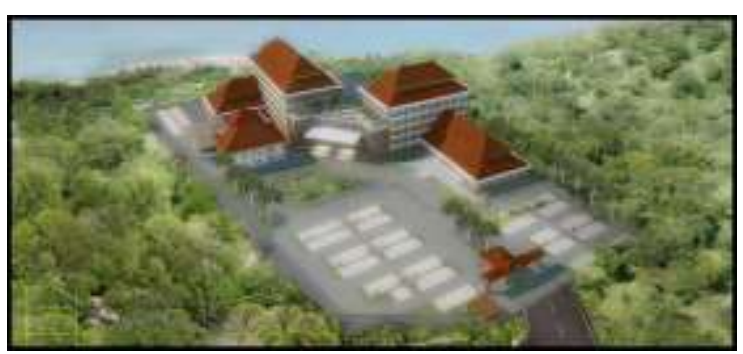

Gambar 11. Eksterior Kawasan Hotel Spa

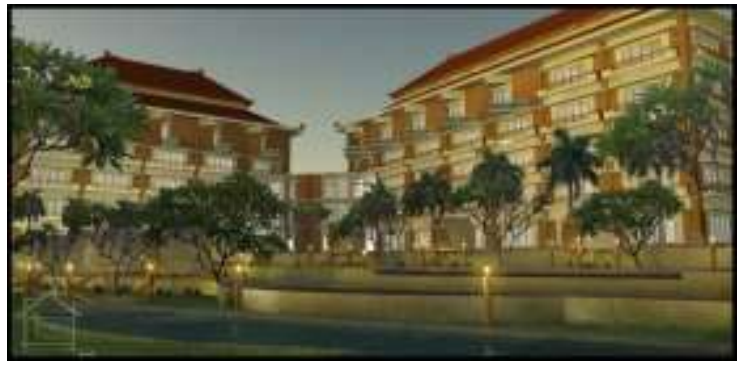

Gambar 12. Area Taman dan Kolam Renang

\section{REFERENSI}

"Artikel Berita Dari Website Martha Tilaar Salon Day Spa." diakses September 6, 2015. http://www.marthatilaarspa.com/sub page.php?page=detail_news\&idconte $\mathrm{nt}=126 \&$ lang $=$ en \& category $=$.

"Berita Resmi Statistik Provinsi Bali No. 35/06/51/6 Th. VIII." Badan Pusat Statistik Provinsi Bali, n.d. diakses Juni 2, 2014.

Budihardjo, Eko. 1986. Architectural Conservation in Bali. Gadjah Mada University Press.

Canizaro, Vincent B. 2012. Architectural Regionalism: Collected Writings on Place, Identity, Modernity, and Tradition. Chronicle Books.

Curtis, William. 1985. Regionalism in Architecture. Singapura: Concept Media.

De Chiara, Joseph, and John Callender. Time Saver Standards for Building Types 2nd Edition.

Gelebet, I Nyoman, and I. G. N. Arinton Puja. 1986. Arsitektur Tradisional Daerah Bali. Badan Pengembangan Kebudayaan dan Pariwisata, Deputi Bidang Pelestarian dan Pengembangan Budaya, Bagian Proyek Pengkajian dan Pemanfaatan Sejarah dan Tradisi Bali.
Gubernur Bali. "PERATURAN DAERAH PROVINSI BALI NOMOR 16 TAHUN 2009 Tentang Rencana Tata Ruang Wilayah Provinsi Bali 20092029," n.d.

Jencks, Charles A. 2009. The Language of Post-Modern Architecture. Rizzoli, 1977.

Jumarani, Louise. The Essence of Indonesian Spa: Spa Indonesia Gaya Jawa dan Bali. PT Gramedia Pustaka Utama.

Marlina, Endy. 2008. Panduan Perancangan Bangunan Komersial. ANDI.

Neufert, Ernst. 1996. Data Arsitek. Jilid I. Jakarta: Erlangga.

Urry, John. 2002. The Tourist Gaze. SAGE.

Widyarta, M. Nanda. 2007. Mencari Arsitektur Sebuah Bangsa: Sebuah Kisah Indonesia. Wastu Lanas Grafika. 